\title{
Behavioral Heterogeneity in the Options Market
}

\section{- Preliminary Draft -}

\author{
March 2008 \\ Bart Frijns \\ Deaprtment of Finance, Auckland University of Technology, New Zealand.
}

\begin{abstract}
Thorsten Lehnert
Limburg Institute of Financial Economics (LIFE), Maastricht University, The Netherlands. Nijmegen Center for Economics (NiCE), Radboud University Nijmegen, The Netherlands.

Remco C.J. Zwinkels ${ }^{1}$

Nijmegen Center for Economics (NiCE), Radboud University Nijmegen, The Netherlands.
\end{abstract}

${ }^{1}$ Corresponding Author: Nijmegen Center for Economics (NiCE), P.O.Box 9108, 6500HK Nijmegen, The Netherlands. T: +31 (24) 36 16235, F: +31 (24) 36 12379, E: r.zwinkels@ @m.ru.nl (Remco Zwinkels). 


\title{
Behavioral Heterogeneity in the Option Market
}

\section{- Preliminary Draft -}

March 2008

\begin{abstract}
$\underline{\text { Abstract }}$
This paper develops and tests a heterogeneous agents model for the option market. Our agents have differing beliefs about the level of volatility of the underlying stock index and trade accordingly. We consider two types of agents: fundamentalists, who are assumed to expect the conditional volatility to return to the unconditional volatility, and chartists who respond solely to noise from the level process. Agents are able to switch between groups according to a multinomial logit switching mechanism. The model simplifies to a GARCH-type specification with time-varying parameters, which depend on the distribution of agents across types. Estimation results for index options on the German DAX30 reveal that different types of traders are also actively involved in trading volatility. We find evidence that the observed patterns in option prices are the result of heterogeneity in expectations about future volatility.
\end{abstract}

Keywords: Heterogeneous Agents, Option Markets, Fundamentalists, Chartists.

JEL-Classification: G12 


\section{Introduction}

Volatility is priced and traded in the options market. If market participants have diverging views about future volatility of e.g. a stock index, they engage in directional volatility bets, for example through the use of option strategies. ${ }^{2}$ If they believe that markets become more volatile, they buy at-the-money puts and calls (a long straddle), since the value usually increases with a rise in volatility. If they believe that volatility is overpriced in the market, they short a straddle. Volatility trading creates uncertainty about the "fair value' of volatility. Differing expectations about future volatility implies that volatility is not constant and that volatility itself becomes volatile. In recent years, stochastic volatility models are successfully used for the purpose of option valuation. The volatility of volatility was found to be in particularly important for the pricing performance of the model (Christoffersen and Jacobs, 2004).

The evidence against the Efficient Market Hypothesis (EMH, see Fama, 1971) has been mounting in the previous decades. In a broad range of markets and using a similarly broad range of techniques, researchers have found evidence against the notion of rationality in financial markets. One area in which the notion of rationality is consistently rejected is in studies using observed (survey) expectations (see Frijns et al., 2008 for experimental evidence or MacDonald, 2000 for an overview). Most surveys focus on the foreign exchange market, but similar results are found for bond and stock markets. A second strand of observations that raises doubts on the EMH is the existence of numerous anomalies in financial markets. Phenomena like excess volatility, small firm effects, overshooting and the January effect cannot be explained by representative agent rational expectation models. Also theoretically one can cast doubt on the EMH. No trade theorems, introduced by Milgrom and Stokey (1982), hypothesize that rational agents will never trade because expectations are equal and all information is discounted in the current market price. Therefore, price changes occur without trade taking place. This is hard to combine with the observation of enormous volume in especially FOREX markets.

\footnotetext{
${ }^{2}$ One alternative for example is to buy or sell an over-the-counter volatility contract like a volatility swap, where e.g. the buy receives the difference between the realized volatility and the fixed swap rate. Another is to trade futures and options on a volatility index. Surprisingly, the volume in these contracts has been disappointing.
} 
One of the responses in the academic literature to the demise of the EMH is the behavioral finance literature (Kahneman and Tversky, 1979 or Barberis et al., 1998, inter alii). The behavioral finance literature steps aside from the notion of rationality and introduces elements from social psychology in economic decision making. Models of behavioral finance are usually geared towards explaining the observed market anomalies. These models can, for example, explain the excess volatility observed in financial markets (e.g. De Long et al., 1990) by the existence of different trader types. ${ }^{3}$

These models, which explain the excess volatility observed in financial markets, are based on the idea that different trader types, through their actions, affect the conditional volatility of the price process. Indeed, Avromov et al. (2006) show that the existence of both types of traders cannot only explain the differences in daily volatility, but can also explain the asymmetry observed in daily volatility.

The literature on heterogeneous expectations in volatility so far has been relatively limited. Guo (1998) assumes that option investors hold heterogeneous expectations about the parameters of the lognormal process of the underlying asset price. Estimation results for S\&P500 index call options indicate that there are two groups: bulls and bears. Ziegler (2002) models two types of agents who differ in their initial beliefs on the dividend process and investigates the effect on option prices. We argue that different types of traders are also actively involved in trading volatility. Although this might not necessarily be the case in the stock market, it is the case when one turns to the option market. Being the only unobserved variable in an option pricing model, volatility plays a pivotal role in the determination of the value of an option. Hence option strategies could be a direct consequence of expectations about future volatility. If different trader types have different expectations about the future volatility of the underlying, this may induce trade and cause volatility to change (see e.g. Carr and Madan (2002)). To evaluate whether different trader types are present, we make use of the heterogeneous agents literature, which argues that due to the presence of agents with bounded rationality expectations about future values may differ. In line with this literature we assume that two different trader types are active in trading volatility, where some traders (termed

\footnotetext{
${ }^{3}$ The existence of different trader types and their impact on volatility has not only been brought forward within the behavioral finance literature, but has also been proposed within the field of market microstructure (see e.g. Kyle, 1985).
} 
fundamentalists) trade on the long-run mean reversion of the conditional volatility to the unconditional volatility and other trader (called chartists) trade on short-run persistence in the volatility process. These traders may change their strategy based on the performance of their strategy compared to the performance of the strategy of the other traders. Interestingly, when combining the strategies of both types of traders we find that our model reduces to an asymmetric GARCH model, but with time-varying coefficients, where the time-variation is due to changes in the proportion of fundamentalists and chartists present in the market. This time variation introduces another interesting feature, namely allowing the volatility process to be locally unstable while guaranteeing global stability. When chartist traders dominate the market their persistence may cause the volatility process to become unstable. However, when the proportion of fundamentalist traders increases, their presence ensures that the volatility process remains stable in the long-run. In this manner, the process can switch between stable and unstable phases, providing an economic interpretation to the notion of volatility clustering observed in financial markets.

When empirically testing our model on option prices we find evidence that support the presence of both types of traders. Over time, the fractions of fundamentalist and chartist traders change and we find evidence that our model outperforms a standard model without switching in terms of pricing performance both in-sample and out-ofsample.

We contribute to the literature on three different grounds. First, we do not assume heterogeneity in beliefs on the price process, but on the volatility process; fundamentally different types of agents with different option strategies are introduced. Second, we allow agents to switch between different strategies instead of assuming fixed proportions and, finally, next to this novel theoretical setup we empirically assess the pricing performance of the model.

The remainder of the paper is organized as follows. Section 2 reviews some of the literature on heterogeneous agent models. In section 3 we present the econometric framework of our model. Section 4 presents the data \& methodology of the estimation procedure. In section 5 we show the results, and section 6 concludes. 


\section{Heterogeneous Agent Models}

Divergence from the assumption of rationality implies that one can introduce heterogeneity in expectations as well; there is only one way of behaving rational, while there are infinite ways of behaving irrational, or boundedly rational. Three explanations for being heterogeneous can be discerned from the literature. First is the existence of asymmetric information. Different market participants are assumed to hold different sets of information, whereby part of the information is common for all participants and part is private. The concept of asymmetric information was first introduced in the New Classical Theory of the macro economy, where agents were assumed to be unable to obtain information that is public in other parts of the economy, and where agents are rational in the Muth (1961) sense in that they use that information that is available to them in the best possible way to form their expectations of a particular variable. Second is the claim that agents might differ in the way (symmetric) information is interpreted. To argue why the difference in interpretation occurs we can follow the rational belief theory due to Kurz (1994), which assumes that heterogeneity of beliefs is caused by the fact that economic agents do not know the structural relations of the economy. Agents only have 'information' or 'empirical knowledge', which is readily observable from the economy. Third and final ground for heterogeneity in expectations is the existence of fundamentally different types of agents. DeLong et al. (1990) formally model the notion of noise traders, which do not get driven out of the market. Frankel and Froot $(1986,1990)$ popularize the view that the foreign exchange market is dominated by two types of market participants that differ in which information they use for forming their expectations. Fundamentalists think of the exchange rate as an economic model, while chartists predominantly use the exchange rate's own history as input in their expectations formation process.

The literature on heterogeneous agents models, or HAMs, continues on the line of thought that there can be fundamentally different types of agents, see Hommes (2006) and LeBaron (2006) for an overview. The literature on heterogeneous agents applied to financial markets aims to describe the evolution of stock price by relaxing the assumption of homogeneity among investors. By allowing for heterogeneity among investors, different types of investors can be classified along with their potential strategies, and one 
can evaluate how likely it is that these traders are active in a market and what the consequences of their trading is for the price and volatility process. Generally, traders are classified in two categories, being either fundamentalists, who trade on the basis of fundamentals, or chartists, who trade on observed patterns in past prices, as first introduced by Frankel and Froot (1986). Revolutionary in the models described in Hommes (2006) is that agents do not only differ, but that they are able to switch between types, conditional on performance. This switching introduces a non-linear model that mixes different regimes, based on economic foundations.

Up till now the majority of studies on HAMs has been conducted in experimental settings. Using either deterministic or stochastic simulation techniques, the presence of different trader types in financial markets can explain some stylized facts of returns from financial markets; see e.g. De Grauwe and Grimaldi (2005, 2006) and Lux (1998). The irregular switching between types induces volatility clustering, heavy tails, slow mean reversion, and excess volatility. To our best knowledge, there is only a handful of papers that directly attempt to estimate a HAM with full-fledged switching mechanism. Boswijk et al. (2007) examine the S\&P500; Westerhoff and Reitz (2005, 2007) look at commodity markets; De Jong et al. (2007) focus on EMS exchange rates. All studies, though, find significant evidence of heterogeneity among traders, and switching between strategies.

\section{The Econometric Framework}

Let $S_{t}$ be the value of an underlying asset at time $t$, and $D$ be the expected cash dividend payments over the lifetime of the option. Then, in a Gaussian discrete-time economy the $(\log )$ return of the asset at time $t\left(r_{t}\right)$ is assumed to follow the following dynamics,

$$
\begin{gathered}
r_{t}=\ln \left(\frac{S_{t}}{S_{t-1}}\right)_{t}+d_{t}=\mu+\sqrt{h_{t}} \varepsilon_{t}, \\
\varepsilon_{t} \mid \Omega_{t-1} \sim N(0,1) \text { under probability measure } P
\end{gathered}
$$

where $d_{t}$ is the dividend yield, $\mu$ is the (conditional) mean of $r_{t}, h_{t}$ is the conditional volatility of the asset and $\varepsilon_{t}$ is a standard normal random variable. It is on the process of $h_{t}$ that we focus in this paper and we assume that there are two different groups of traders, 
so-called fundamentalists and chartists, which have different expectations regarding the future evolution of $h_{t}$.

Let $h_{t+1}^{F}$ be the prediction of the conditional volatility for the fundamentalists. These fundamentalists are assumed to trade on the basis of mean reversion, where they expect the conditional volatility mean-reverting to the unconditional volatility. Their best prediction for the volatility process is

$$
h_{t+1}^{F}=h_{t}+\alpha\left(h_{t}-\bar{h}\right) \text {, }
$$

where $\bar{h}$ is the long-run unconditional volatility ${ }^{4}$ and $\alpha$ measures the speed at which the fundamentalists expect the volatility process to mean revert. Since volatility needs to remain positive with probability $1, \alpha$ is bounded between $[-2,0]$, but is typically expected to be between $[-1,0]$. When $\alpha \rightarrow 0$ the process becomes very persistent and little mean reversion takes place. When $\alpha \rightarrow-1$ the process reverts back to the unconditional volatility almost immediately. Equation (2) reveals that fundamentalists essentially follow a $\operatorname{GARCH}(1,0)$, not taking into account any shocks in the volatility process.

The chartists do not believe in mean reversion, but trade on recently observed shocks in the market. Given the current level of volatility, they use recently observed shocks to predict the future level of conditional volatility. Given that conditional volatility behaves differently in the presence of positive or negative shock, we allow for an asymmetric impact of these shocks (Glosten, Jagannathan and Runkle, 1993). We therefore define their prediction of the volatility process as

$$
h_{t+1}^{C}=h_{t}+\beta_{0}\left(\sqrt{h_{t}} \varepsilon_{t}^{+}\right)^{2}+\beta_{1}\left(\sqrt{h_{t}} \varepsilon_{t}^{-}\right)^{2}
$$

where $h_{t+1}^{C}$ is the volatility prediction of the chartists, $\varepsilon_{t}^{+}\left(\varepsilon_{t}^{-}\right)$is the past positive (negative) shock in the volatility process and $\beta_{0}\left(\beta_{l}\right)$ measures the extent to which chartists incorporate positive (negative) shocks into their prediction.

\footnotetext{
${ }^{4}$ When we empirically implement the model, we assume that $\bar{h}$ is equal to the variance of the underlying return series calculated over the previous 250 trading days with a moving window.
} 
Because we have defined a market where only these two types of traders are present, the conditional volatility that is observed in the market $\left(h_{t+1}\right)$ is a function of the predictions of chartists and fundamentalists and the fraction at which each trader type is represented in the market. Since both strategies involve no particular skill or information from traders, traders can switch to either strategy at any point in time without incurring transaction costs. Let $w_{t}$ be the fraction of fundamentalists present in the market. Then a natural choice for $w_{t}$ is a rule that considers the profitability or pricing error of following a fundamentalist strategy. ${ }^{5}$ We define $w_{t}$ as a multinomial logit switching rule, as first introduced by Brock and Hommes (1997, 1998), where the switching depends on the absolute forecast error of fundamentalists versus chartists. The switching rule is given as

$$
w_{t}=\left(1+e^{\gamma\left(a b s\left(\frac{\ln \left(h_{t}^{F}\right)-\ln \left(h_{t}\right)}{\ln \left(h_{t}\right)}\right)-a b s\left(\frac{\ln \left(h_{t}^{C}\right)-\ln \left(h_{t}\right)}{\ln \left(h_{t}\right)}\right)\right)}\right)^{-1},
$$

where $\gamma$ measures the sensitivity of market participants (fundamentalists or chartists) to their respective percentage forecasting errors in terms of volatility and is expected to be between 0 and infinity. This sensitivity of choice parameter can be interpreted as the status quo bias of traders. With $\gamma=0$ agents are distributed uniformly across types. As $\gamma$ increases, agents become increasingly sensitive to differences in forecasting performance between the strategies. In the limiting case, as $\gamma \rightarrow \infty$, all agents directly switch to the more profitable rule, such that $w_{t}$ is either 0 or 1 . Given this definition, $w_{t}$ will always be strictly bounded between 0 and 1 .

With the given weights and the different trading strategies we can now establish the process for the conditional volatility. Since the conditional volatility is a consequence of the proportion of market participants following each strategy it is computed as a weighted average of the fundamentalist and the chartist volatility prediction,

\footnotetext{
${ }^{5}$ An example for the definition of $w_{t}$ is the profits fundamentalists make relative to the chartist on an option strategy that involves straddles. When e.g. fundamentalists expect volatility to increase they will go long in a straddle and vice versa. If their strategy works and pays off well relative to the strategy of the chartists, more traders may be inclined to follow this fundamental strategy and hence the proportion of fundamentalists will increase. If their strategy does not work and performs poorly relative to chartists, more traders may be inclined to follow a chartist strategy in the future.
} 


$$
h_{t+1}=w_{t} h_{t+1}^{F}+\left(1-w_{t}\right) h_{t+1}^{C} .
$$

The particular specification of $w_{t}$ ensures that more market participants follow a particular trading strategy the better the strategy performed in the previous period. Therefore, if the fundamentalist predicts volatility more accurately than the chartist, $w_{t+1}$ increases. A better prediction of the chartists consequently reduces $w_{t+1}$.

Equation (5) defines the process for the conditional volatility and shows that this is a weighted average of the conditional volatility predictions of chartists and fundamentalists. Subsequently, we provide an economic interpretation of (5). We start by substituting (2) and (3) into (5). After rewriting we obtain

$$
h_{t+1}=-w_{t} \alpha \bar{h}+\left(1+w_{t} \alpha\right) h_{t}+\left(1-w_{t}\right) \beta_{0}\left(\sqrt{h_{t}} \varepsilon_{t}^{+}\right)^{2}+\left(1-w_{t}\right) \beta_{1}\left(\sqrt{h_{t}} \varepsilon_{t}^{-}\right)^{2}
$$

or

$$
h_{t+1}=\bar{h}_{t}+\alpha_{t} h_{t}+\beta_{0, t}\left(\sqrt{h_{t}} \varepsilon_{t}^{+}\right)^{2}+\beta_{1, t}\left(\sqrt{h_{t}} \varepsilon_{t}^{-}\right)^{2}
$$

where $\bar{h}_{t}=-w_{t} \alpha \bar{h}, \alpha_{t}=\left(1+w_{t} \alpha\right), \beta_{0, t}=\left(1-w_{t}\right) \beta_{0}$, and $\beta_{1, t}=\left(1-w_{t}\right) \beta_{1}$. Equation (7) shows that the model essentially reduces to a GJR-GARCH( $(1,1)$ model with time varying coefficients. The time variation in these coefficients is driven by the profitability of being a fundamentalist or a chartist.

Apart from this time variation, there are several interesting features about our model. Firstly, since our model reduces to a standard GJR-GARCH, we can provide an economic interpretation of the GARCH model. Up till now the GARCH model has mainly been motivated by the empirical observation of time variation in conditional volatility. The model proposed provides an economic interpretation of the source of time variation in volatility and of GARCH effects. The model shows that the mean reversion of the conditional volatility is driven by the presence of fundamentalists, and that persistence in volatility is driven by the presence of the chartists. When very few chartists 
are present in the market, mean reversion would occur at a faster rate than when many chartists are present. Also, the impact of news shocks on the conditional volatility is solely driven by the presence of chartists, who expect recent news to be informative about the future level of volatility. The GARCH effect and ARCH effect can therefore be explained by the presence of these two types of traders in the market.

A second interesting feature of the model concerns the stability conditions of (7). Under normal circumstances, fundamentalists follow a strategy that ensures that the conditional volatility remains bounded. However, the chartist strategy is an unstable strategy when $\beta_{0}$ and $\beta_{1}$ are positive and volatility predicted by chartists will not remain bounded. However, the fact that both types of traders are present and $w_{t}$ fluctuates over time allows the volatility process (7) to be locally unstable, while guaranteeing stability of the GARCH process in the long run. Whether (7) is stable in the long run depends on the parameter values for $\alpha, \beta_{0}$ and $\beta_{1}$ and is an issue that will be addressed in the empirical section.

A third feature about the model is the time varying unconditional volatility. This time variation in unconditional volatility is not caused by slow-moving change in the underlying unconditional volatility (as suggested by Engle and Lee, 1999), but is also driven by the amount of fundamentalists or chartists present.

The model presented above represents the most simplistic form fundamentalist and chartist behavior. There are several extensions possible to the strategies for both types of traders. Firstly, we can extend the fundamentalist strategy by allowing for dynamics in the "unconditional volatility". Such types of model follow from Engle and Lee (1999) and are often referred to as two-component GARCH models. Allowing for such additional dynamics can be done straightforwardly, and would imply that (4) takes the form of a GJR-GARCH $(2,2)$. Secondly, chartists may also consider other stochastic variables, such as trading volumes, number of transactions, etc. The stochastic variables can be added to the model.

The model presented in section 3 could essentially be applied to any type of security in financial markets. However, in the current paper we estimate the model on 
option prices. From Black and Scholes we know that the only unknown variable in the option pricing model is the volatility. Hence trading in options is essentially trading on the expectations about the future volatility of the underlying. The following section discusses the data and methodology followed in estimating the model and subsequently we summarize the empirical results.

\section{Data and Methodology}

We use daily closing DAX 30 index options and futures prices for a one year period from January 2000 until December 2000. The raw data set is directly obtained from the EUREX, European Futures and Options Exchange. The market for DAX index options and futures is the most active index options and futures market in Europe.

For index options the expiration months are the three nearest calendar months, the three following months within the cycle March, June, September and December, as well as the two following months of the cycle June, December. For index futures, the expiration months are the three nearest calendar months within the cycle March, June, September and December. The last trading day is the third Friday of the expiration month, if that is an exchange trading day; otherwise on the exchange-trading day immediately prior to that Friday.

We exclude options with less than one week and more than 25 weeks until maturity and options with a price of less than 2 Euro to avoid liquidity-related biases and because of less useful information on volatilities. We filter the available option prices and include all options that are actively traded, inside or outside the $10 \%$ absolute moneyness interval. In practice, in volatile periods deep out-of-the money options are highly informative if they are actively traded. As a result, each day we use a minimum of 3 , but typically 4 different maturities for the calibration.

Insert Table 1 Here 
The DAX index calculation is based on the assumption that the cash dividend payments are reinvested. Therefore, when calculating option prices, theoretically we do not have to adjust the index level for the fact that the stock price drops on the ex-dividend date. But the cash dividend payments are taxed and the reinvestment does not fully compensate for the decrease in the stock price. Therefore, in the conversion from e.g. futures prices to the implied spot rate, one empirically observes a different implied dividend adjusted underlying for different maturities. For this reason, we work with the adjusted underlying index level implied out from futures or option market prices.

In a nutshell, the option pricing procedure boils down the following. First of all, the dividend adjusted value for the underlying is determined for a certain day; in our case, that is the DAX30 on January 1st 2000. Next, a set of options is observed with different times to maturity and different strikes for that same day. Using Monte Carlo simulations, the model generates a certain forecasts for all the different expiration dates. In other words, it starts off from the observed dividend-adjusted underlying of today, and iterates forward until expiration. Next, option prices are calculated with these forecasts using the standard Black and Scholes approach, and compared with the empirically observed option prices. The optimisation procedure then consists of minimizing the root-meansquared pricing error of the total set of options per day. The equilibrium set of coefficients is then used as starting values for the optimization procedure for the next day. This whole procedure is repeated for each trading day in the dataset. In particular we are using the following procedure for one particular day to price options on the following trading day:

First, we compute the implied interest rates and implied dividend adjusted index rates from the observed put and call option prices. We are using a modified put-call parity regression proposed by Shimko (1993). The put-call parity for European options reads:

$$
c_{i, j}-p_{i, j}=\left[S_{t}-P V\left(D_{j}\right)\right]-X_{i} e^{-r_{j}\left(T_{j}-t\right)}
$$

where $c_{i, j}$ and $p_{i, j}$ are the observed call and put closing prices, respectively, with exercise prices $X_{i}$ and maturity $\left(T_{j}-t\right), P V\left(D_{j}\right)$ denotes the present value of dividends to be paid 
from time $t$ until the maturity of the options contract at time $T_{j}$ and $r_{j}$ is the continuously compounded interest rate that matches the maturity of the option contract. Therefore, we can infer a value for the implied dividend adjusted index for different maturities, $S_{t^{-}}$ $P V\left(D_{j}\right)$, and the continuously compounded interest rate for different maturities, $r_{j}$. To ensure that the implied dividend adjusted index value is a non-increasing function of the maturity of the option, we occasionally adjust the standard put-call parity regression. Therefore, we control and ensure that the value for $S_{t}-P V\left(D_{j}\right)$ is decreasing with maturity, $T_{j}$. Since we are using closing prices for the estimation, one alternative is to use implied index levels from DAX index futures prices assuming that both markets are closely integrated.

Second, we estimate the parameters of the particular models by minimizing the loss function. Parameters of the model are calibrated by minimizing the root mean squared absolute pricing error between the market prices and the theoretical option prices:

$$
R M S E=\sqrt{\frac{1}{N} \min \sum_{i=1}^{n} \sum_{j=1}^{m_{i}}\left(\hat{c}_{i, j}-c_{i, j}\right)^{2}}
$$

where $N$ is the total number of call options evaluated, the subscript $i$ refers to the $n$ different maturities and subscript $j$ to the $m_{i}$ different strike prices in a particular maturity series $i$.

Given reasonable starting values, we price European call options with exercise price $X_{i}$ and maturity $T_{j}$. Using well-known optimization methods (e.g. Newton-Raphson method), we obtain the parameter estimates that minimize the loss function. The goodness of fit measure for the optimization is the mean squared valuation error criterion.

Third, having estimated the parameters in-sample, we turn to out-of-sample valuation performance and evaluate how well each day's estimated models value the traded options at the end of the following day. We filter the available option prices according to our criteria for the in-sample calibration. The futures market is the most liquid market and the options and the futures market are closely integrated, therefore it can also be assumed that the futures price is more informative for option pricing than just 
using the value of the index. For every observed futures closing price we can derive the implied underlying index level and evaluate the option. Given a futures price $F_{j}$ with time to maturity $T_{j}$, spot futures parity is used to determine $S_{t}-P V\left(D_{j}\right)$ from

$$
\mathrm{S}_{t}-P V\left(D_{j}\right)=F_{j} \mathrm{e}^{-\mathrm{r}_{\mathrm{j}} \mathrm{T}_{\mathrm{j}}}
$$

where $P V\left(D_{j}\right)$ denotes the present value of dividends to be paid from time $t$ until the maturity of the options contract at time $T_{j}$ and $r_{j}$ is the continuously compounded interest rate (the interpolated EURIBOR rate) that matches the maturity of the futures contract (or time to expiration of the option). If a given option price observation corresponds to an option that expires at the time of delivery of a futures contract, then the price of the futures contract can be used to determine the quantity $S_{t}-P V\left(D_{j}\right)$ directly.

The maturities of DAX index options do not always correspond to the delivery dates of the futures contracts. In particular for index options the two following months are always expiration months, but not necessarily a delivery month for the futures contract. When an option expires on a date other than the delivery date of the futures contract, then the quantity $S_{t}-P V\left(D_{j}\right)$ is computed from various futures contracts. Let $F_{1}$ be the futures price for a contract with the shortest maturity, $T_{1}$ and $F_{2}$ and $F_{3}$ are the futures prices for contracts with the second and third closest delivery months, $T_{2}$ and $T_{3}$, respectively. Then the expected future rate of dividend payment $\mathrm{d}$ can be computed via spot-futures parity by:

$$
\mathrm{d}=\frac{\mathrm{r}_{3} \mathrm{~T}_{3}-\mathrm{r}_{2} \mathrm{~T}_{2}-\log \left(\mathrm{F}_{3} / \mathrm{F}_{2}\right)}{\left(\mathrm{T}_{3}-\mathrm{T}_{2}\right)}
$$

Hence, the quantity $S_{t}-P V(D)=S_{t} e^{-d T}$ associated with the option that expires at time $T$ in the future can be computed by ${ }^{6}$

$$
S_{t} e^{-d T}=F_{1} e^{\left(-\left(r_{1}-d\right) T_{1}-d T\right)} .
$$

\footnotetext{
${ }^{6}$ See e.g. the appendix in Poteshman (2001) for details.
} 
This method allows us to perfectly match the observed option price and the underlying dividend adjusted spot rate. Given the parameter estimates and the implied dividend adjusted underlying we can calculate option prices and compare them to the observed option prices of traded index options. For the out-of-sample part the same loss functions for call options are used. The prediction performance of the various models are evaluated and compared by using the root mean squared valuation error criterion. We compare the predicted option values with the observed prices for every traded option. We repeat the whole procedure over the out-of-sample period and conclude, which model minimizes the out-of-sample pricing error.

In order to evaluate options, the physical process has to be transformed to a riskneutral process. We make use of the Local Risk Neutral Valuation Relationship (LRNVR) developed in Duan (1995). Under the LRNVR the conditional variance remains unchanged, but under the pricing measure $Q$ the conditional expectation of $r_{t}$ is equal to the risk free rate $r_{f}$ :

$$
E^{Q}\left[\exp \left(r_{t}\right) \mid \Omega_{t-1}\right]=\exp \left(r_{f}\right)
$$

The risk-neutral Gaussian process reads:

$$
\begin{gathered}
r_{t}=\ln \left(\frac{S_{t}-P V_{t}(D)}{S_{t-1}-P V_{t-1}(D)}\right)_{t}=r_{f}-\frac{1}{2} \sigma_{t}^{2}+\sqrt{h_{t}} \varepsilon_{t}, \\
\varepsilon_{t} \mid \Omega_{t-1} \sim N(0,1) \text { under the risk-neutralized probability measure } Q
\end{gathered}
$$

In Equation (14), $\varepsilon_{t}$ is not necessarily normal, but to include the Black-Scholes model as a special case we typically assume that $\varepsilon_{t}$ is a Gaussian random variable. The locally risk-neutral valuation relationship ensures that under the risk neutral measure $Q$, the volatility process satisfies 


$$
\operatorname{Var}^{Q}\left[r_{t} \mid \Omega_{t-1}\right]=\operatorname{Var}^{P}\left[r_{t} \mid \Omega_{t-1}\right]=h_{t}
$$

A European call option with exercise price $X$ and time to maturity $T$ has at time $t$ price equal to:

$$
c_{t}=\exp (-r T) E_{t}^{Q}\left[\max \left(S_{t}-X, 0\right) \mid \Omega_{t-1}\right]
$$

For this kind of derivative valuation models with a high degree of path dependency, computationally demanding Monte Carlo simulations are commonly used for valuing derivative securities. We use the recently proposed simulation adjustment method, the empirical martingale simulation (EMS) of Duan and Simonato (1998), which has been shown to substantially accelerate the convergence of Monte Carlo price estimates and to reduce the so called 'simulation error'.

In the empirical part of the paper, we model the expectations of conditional volatility of fundamentalists (and chartists) in an EGARCH setting, which is motivated by the empirical data fitting (see Lehnert (2003)). Applying a standard GARCH framework resulted in numerous violations of parameters in their permissible parameter space. The EGARCH setting resolves these issues, as it imposes no restrictions on the parameter space (see Nelson, 1991).

\section{Results}

This section presents the empirical results of the option pricing application of our heterogeneous agents model for the second moment. First, we present one specific path from the Monte Carlo simulations in order to gain somewhat more feeling on the behaviour of the proposed model. Second we focus on both the estimation results and the stability of the estimates through time. Finally, we look at the pricing errors of our model, both in-sample and out-of-sample. The estimation exercises are conducted in a setting

with and without switching. This allows us to examine the direct effect of introducing more flexibility in the model; in other words, it allows us to see the advantage of our model over a standard GARCH. 
Insert Figure 1 Here

Figure 1 presents a close-up of a one simulation path out of 10.000 in the Monte Carlo setup; it uses the (optimized) coefficients from a random day, May $5^{\text {th }}$ in this case ${ }^{7}$. A number of observations can be made. As one would expect, the volatility $h$ lies between the expectations of the fundamentalists $h^{F}$ and chartists $h^{C}$. The distance between the three is governed by the weight $w_{t}$. Weights fluctuate continuously around the benchmark of one half with a minimum of 0.14 and maximum of 0.81 . The nature of the two groups is clearly illustrated by the course of the volatility process. High spikes in volatility always coincide with low weights; i.e., a relatively high volatility is caused by the fact that the market is dominated by chartists. The most clear example of this can be seen around observation number 40 where $w$ reaches its minimum and $h$ its maximum. The reverse is true as well; when fundamentalist make up over $80 \%$ of the market around period 70, volatility drops towards its long-run value. Therefore, fundamentalists are stabilizing, and chartists destabilizing. None of the groups gets driven out of the market, and both groups experience periods of dominance.

Insert Table 2 Here

\footnotetext{
${ }^{7}$ The coefficients are given by $\alpha=-0.087 ; \beta_{0}=-0.365 ; \beta_{1}=0.337$; and $\gamma=40.450$.
} 
Table 2 presents the estimation results of the option pricing application of the heterogeneous agents model; the distributional characteristics of the estimates over time are depicted. Overall, we observe that all coefficients have the sign and magnitude as hypothesized by the model. Both fundamentalists and chartists appear to be active on the market; their individual effects on the variance process are as expected (stabilizing and destabilizing, respectively). Also, we find significant evidence of switching between the two rules.

Focusing on the static setup first (Panel A); the mean-reversion parameter $\alpha$ is negative throughout the sample, implying that fundamentalists consistently apply a stabilizing expectation formation rule. They therefore introduce a mean reverting dynamics into the variance process, as they expect the variance to return to the long run volatility. The absolute magnitude of the mean estimate of $\alpha$ indicates that fundamentalists expect on average $4 \%$ of the excess volatility to disappear in the next period. The average estimated local volatility, i.e. the starting value for the volatility dynamics, is estimated to be equal to $27 \%$ (annualized), which is very much in line with the time series volatility of the DAX index in that period.

Parameter estimates for the chartist expectation formation rule in the model, $\beta_{0}$ and $\beta_{1}$, have the expected sign as well. The results for this asymmetric setup imply that there is a clear leverage effect: Positive shocks in the level result in a reduction of the variance $\beta_{0}<0$; negative shocks in the level result in an increase of the variance $\beta_{1}>0$. Therefore, negative shocks in the level have a destabilizing effect to the variance process because of the chartists' expectation formation rule.

The results for the switching setup, in Panel B, are generally consistent with the static setup. The difference, the sensitivity of choice parameter $\gamma$, is positive throughout the sample. This implies that the switching mechanism functions as a positive feedback rule. In other words, the positive sign of the coefficient indicates that agents switch towards the group with the smallest forecasting error. The magnitude of $\gamma$ is conditional on the functional form of the profit function (in our case, a loss function consisting of the percentage forecasting error). Therefore, it is not possible to make any statements about the sensitivity to profit differences of traders in the option market at this time. We will, 
however, be able to say something about the evolution of individual's behaviour over time in the sensitivity analysis below.

As additional empirical evidence for our model, we examined both the in-sample and out-of-sample pricing errors. The results for the models with and without switching are depicted in the final two columns of Table 2. Results suggest that the assumption that agents always switch to the more profitable forecasting rule is very much supported by the data. Comparing Panel A and B reveals that our most sophisticated model outperforms the benchmark with on average $€ 0.92$ for the in-sample and $€ 0.49$ for the out-of-sample pricing error. In other words, next to introducing a more intuitive appeal to volatility models, our heterogeneous agents setup for the second moment also proves to be more effective in explaining and forecasting option prices.

To our best knowledge, a heterogeneous agents model has never been applied to the options market. We can, however, compare our results with related literature. First of all, the signs and magnitudes of the chartist expectation formation function are directly comparable to the standard EGARCH-results, due to Nelson (1991). The relative impact of positive versus negative shocks corroborates previous findings; the typical results for the leverage effect indicate that the relative effect of negative shocks on the variance process is larger than the positive shocks. Second, our results are directly in line with previous findings on estimates of heterogeneous agents models for alternative markets. Boswijk et al. (2007) find significant evidence of the co-existence of chartists and fundamentalist for the S\&P500 from 1870 to 2006; De Jong et al. (2007) present similar results for the British Pound during the EMS crisis. Our results on the switching mechanism, however, are stronger compared to Boswijk et al. (2007) and De Jong et al. (2007); evidence for switching is limited given their estimate of the switching parameter. This implies that traders in the options market are more prone to change their strategy in response to a difference in profits compared to traders in the S\&P500 or foreign exchange market.

Given that the model is estimated for different maturities and levels of moneyness for each day of the year, we can examine the stability of the estimated coefficients during the estimation process. By following the evolution of the estimated coefficients, we will 
be able to say something about the conditional behaviour of heterogeneous traders. Figure 2 depicts the development of the coefficient estimates over time.

Insert Figure 2 Here

Figure 2 displays the development of the two expectation formation functions, fundamentalists and chartists, and the intensity of choice parameter. Overall, the parameters of the fundamentalist and chartist expectation formation functions are relatively stable; $\alpha, \beta_{0}$ and $\beta_{1}$ move in a relative small band within the region you expect them to be.

At around two-thirds of the sample $\alpha, \beta_{0}$ and $\beta_{1}$ start moving towards zero, while $\gamma$ becomes larger and more volatile. This evolution of the parameters can be directly explained by the logic of the underlying heterogeneous agents model. Apparently, the volatility in the underlying is relatively constant in this middle period, which can be seen from the fact that the coefficients of the expectation formation functions go to zero. Both groups form their expectation as the most recently observed volatility, plus some correction term; as the correction term goes to zero, agents expect a constant volatility. As both fundamentalists and chartists expect small innovations to the volatility process, the profit difference between the two strategies as well as the forecasting error itself will be small. As the forecasting errors are small, large shifts in $\gamma$ will not induce large shifts in the distribution of weights over strategies (see Equation 4). This is exactly why the estimate of $\gamma$ shows large shifts in this period.

Insert Figure 3 Here 
Figure 3 presents the evolution of the estimated local volatility and the in-sample pricing error of our model. There is a clear positive correlation between the estimated fundamental volatility and the pricing error. Consistent with previous literature, we find that volatility shows distinctive periods of high and low volatility. Interestingly, the local volatility estimates exactly fluctuate around the long-run volatility level estimated from return data.

\section{Conclusions}

In this paper we introduce a model of behavioral volatility trading. Being the only unobserved variable in an option pricing model, volatility plays a pivotal role in the determination of the value of an option. Our market consists of two types of agents that have different views on volatility and trade accordingly. Fundamentalists are expecting the conditional volatility to mean revert to a long-run volatility level. Chartists on the other hand respond solely on noise from the level process and bid up (down) volatility if they receive a negative (positive) signal from the stock market. Depending on the profitability of their strategy, agents are able to switch between groups according to a multinomial logit switching mechanism. The model is shown to reduce to a GJR$\operatorname{GARCH}(1,1)$ with time varying coefficients. The difference, however, lies in the fact that we provide a behavioral underpinning; also, time variation in the coefficients is dependent on trader behavior.

In an application of the model to DAX index options, using the GARCH option pricing model, we find evidence that different types of traders are actively involved in trading volatility. Both fundamentalists and chartists are shown to be active in the options markets, and both groups are consistently present. Hence, we find evidence that observed option prices are the result of heterogeneity in expectations about future volatility. Also, we find evidence of switching between the groups; that is, at certain points in time the market is dominated by mean-reverting fundamentalists, at other points by destabilizing chartists. Introducing the possibility to switch gives a substantial reduction in both in- and 
out-of-sample pricing errors. In other words, volatility traders indeed change their forecasting behavior dependent on the relative profitability.

Extensions to the current results are both possible and necessary. Our current dataset only comprises of call-options for a limited time span. More data will obviously yield more confidence in the results. The estimation procedure as it is now estimates the model daily; using the data as a panel, so using both the time-series as the cross-sectional variation, would make it possible to construct standard errors around the estimates.

It would also be interesting to experiment with alternative specifications of the model. Think of alternative profit functions, as is common in the heterogeneous agents literature. Also, the expectation formation functions are flexible to incorporate numerous different specifications, including ones with exogenous information. 


\section{References}

Avromov, D., T. Chordia and A. Goyal (2006). The Impact of Trades on Daily Volatility, Review of Financial Studies 19: 1241-1277.

Barberis, N., A. Shleifer, and R. Vishny (1998). A Model of Investor Sentiment, Journal of Financial Economics 49: 307-343.

Boswijk, H.P., C.H. Hommes and S. Manzan (2007). Behavioral Heterogeneity in Stock Prices, Journal of Economic Dynamics and Control, forthcoming.

Brock, W. and C. Hommes (1997). A Rational Route to Randomness, Econometrica 69: 1059-1095.

Brock W. and C. Hommes (1998). Heterogeneous Beliefs and Routes to Chaos in a Simple Asset Pricing Model, Journal of Economic Dynamics and Control 22: 1235-1274.

Carr, P. and D. Madan (2002). Towards a Theory of Volatility Trading. NYU Working Paper.

Christoffersen, P. and K. Jacobs (2004). Which GARCH Model for Option Valuation?, Management Science 50: 1204-1221.

De Long, J.B., A. Shleifer, L.H. Summers, and R.J. Waldmann (1990). Noise trader risk in Financial markets, Journal of Political Finance 98: 703-738.

Duan, J.-C. and J.-G. Simonato (1998), "Empirical Martingale Simulation for Asset Prices", Management Science 44, 1218-1233.

Duan, J.-C. (1995), "The GARCH Option Pricing Model", Mathematical Finance 5, 1332.

Engle, R. and G. Lee (1999). A Permanent and Transitory Component Model of Stock Return Volatility, In: Engle, R. and H. White (eds.), Cointegration, Causality, and Forecasting: A Festschrift in Honour of Clive W.J. Granger. Oxford University Press, pp. 475-497.

Hommes, C.H. (2006). Heterogeneous Agents Models in Economics and Finance, In: Tesfatsion, L. and Judd, K.L. (eds.), Handbook of Computational Economics, Volume 2: Agent-Based Computational Economics, Elsevier Science.

Fama, E. (1971). Risk, Return, and Equilibrium, Journal of Political Economy 79(1):3055. 
Frankel, J.A. and Froot, K.A. (1986). Understanding the US Dollar in the Eighties: The Expectations of Chartists and Fundamentalists, Economic Record, 62(supplement): 2438.

Frankel, J.A. and Froot, K.A. (1990). Chartists, Fundamentalists, and Trading in the Foreign Exchange Market, American Economic Review, 80(2):181-185.

Frijns, B., Koellen, E. and T. Lehnert (2008). On the Determinants of Portfolio Choice, Journal of Economic Behavior and Organization (forthcoming).

Glosten L., R. Jagannathan and D. Runkle (1993). Relationship between the Expected Value and the Volatility of the Nominal Excess Return on Stocks, Journal of Finance, 48: 1779-1801.

Grauwe, De. P. and M. Grimaldi (2005). Heterogeneity of Agents, Transaction Costs and the Exchange Rate, Journal of Economic Dynamics and Control 29: 691-719.

Grauwe, De. P. and M. Grimaldi (2006). Exchange Rate Puzzles: A Tale of Switching Attractors, European Economic Review 50(1): 1-33.

Guo, C. (1998). Option Pricing with Heterogeneous Expectations, The Financial Review 33: 81-92.

De Jong, E., W. Verschoor and R. Zwinkels (2007). A Heterogeneous Route to the EMS Crisis, Applied Economics Letters (forthcoming).

Kahneman, D., and A. Tversky (1979). Prospect Theory: An Analysis of Decision under Risk, Econometrica, XVLII: 263-291.

Kurz, M. (1994). On the Structure and Diversity of Rational Beliefs, Economic Theory, 4(6): 877-900.

LeBaron, B., W.B. Arthur and R. Palmer (1999). Time Series Properties of an Artificial Stock Market, Journal of Economic Dynamics and Control 23: 1487-1516.

Lee, W. Y., Jiang, C. X. and Indro, D.C. (2002), "Stock market volatility, excess returns, and the role of investor sentiment," Journal of Banking and Finance, Vol. 26, pp. 22772299.

Lehnert, T. (2003)", "Explaining Smiles: GARCH Option Pricing with Conditional Leptokurtosis and Skewness, Journal of Derivatives 10, 3, 27-39.

Lux, T. (1998). The Socio-Economic Dynamics of Speculative Markets: Interacting Agents, Chaos and the Fat Tails of Return Distribution. Journal of Economic Behavior and Organization 33: 143-165. 
MacDonald, R. (2000). Expectations Formation Risk in Three Financial Markets: Surveying what the Surveys Say, Journal of Economic Surveys 14(1): 69-100.

Milgrom, P. and N. Stokey (1982). Information, Trade, and Common Knowledge, Journal of Economic Theory 26(1): 17-27.

Muth, J.F. (1961). Rational Expectations and the Theory of Price Movements, Econometrica, 29(3): 315-335.

Nelson, D.B., 1991, Conditional Heteroskedasticity in Asset Returns: A New Approach, Econometrica 59(2):347-370.

Poteshman, A.M. (2001), "Underreaction, Overreaction, and Increasing Misreaction to Information in the Option Market", Journal of Finance 56, 3, 851-876.

Reitz, S. and F.H. Westerhoff (2003). Nonlinearities and Cyclical Behavior: the Role of Chartists and Fundamentalists. Studies in Nonlinear Dynamics and Econometrics 7(4), 3.

Reitz, S. and F. Westerhoff (2006): Commodity price cycles and heterogeneous speculators: A STAR-GARCH model. Empirical Economics, in press.

Reitz, S. and F. Westerhoff. (2005): Commodity price dynamics and the nonlinear market impact of technical traders: empirical evidence for the U.S. corn market. Physica A: Statistical Mechanics and its Application 349: 641-648.

Ziegler, A. (2002). State-price Densities under Heterogeneous Beliefs, the Smile-Effect, and Implied Risk Aversion. European Economic Review 46: 1539-1557. 


\section{Tables and Figures}

Table 1: Number of Observations

\section{Trading Days to Expiration}

\begin{tabular}{|c|c|c|c|c|c|c|c|}
\hline \multirow[b]{2}{*}{ Moneyness } & \multicolumn{2}{|c|}{$<21$} & \multicolumn{2}{|c|}{$[21,63]$} & \multicolumn{2}{|c|}{$>63$} & \multirow[b]{2}{*}{ Total } \\
\hline & Total & $\begin{array}{c}\text { Daily } \\
\text { Median }\end{array}$ & Total & $\begin{array}{c}\text { Daily } \\
\text { Median }\end{array}$ & Total & $\begin{array}{c}\text { Daily } \\
\text { Median }\end{array}$ & \\
\hline$<0.92$ & 909 & 3 & 634 & 3 & 1712 & 7 & 3255 \\
\hline$[0.92,0.96)$ & 2918 & 9 & 1017 & 5 & 728 & 3 & 4663 \\
\hline$[0.96,1.00)$ & 2034 & 7 & 1816 & 7 & 1074 & 4 & 4924 \\
\hline$[1.00,1.04)$ & 753 & 7 & 818 & 3 & 2791 & 10 & 4362 \\
\hline$>1.04$ & 1444 & 6 & 1030 & 5 & 1728 & 7 & 4202 \\
\hline Total & 8058 & 32 & 5315 & 23 & 8033 & 31 & 21406 \\
\hline
\end{tabular}


Table 2: Parameter Estimates

\begin{tabular}{|c|c|c|c|c|c|c|c|}
\hline & Alpha & Gamma & Beta0 & Beta1 & Local & $\begin{array}{c}\text { Pricing Error } \\
\text { (In-sample) }\end{array}$ & $\begin{array}{c}\text { Pricing Error } \\
\text { (Out-of- } \\
\text { Sample- } \\
\text { sample) }\end{array}$ \\
\hline \hline & & & & & & & \\
\hline & & & & & & & \\
\hline & & & & & & \\
\hline \\
\hline
\end{tabular}


Figure 1: Simulation Path

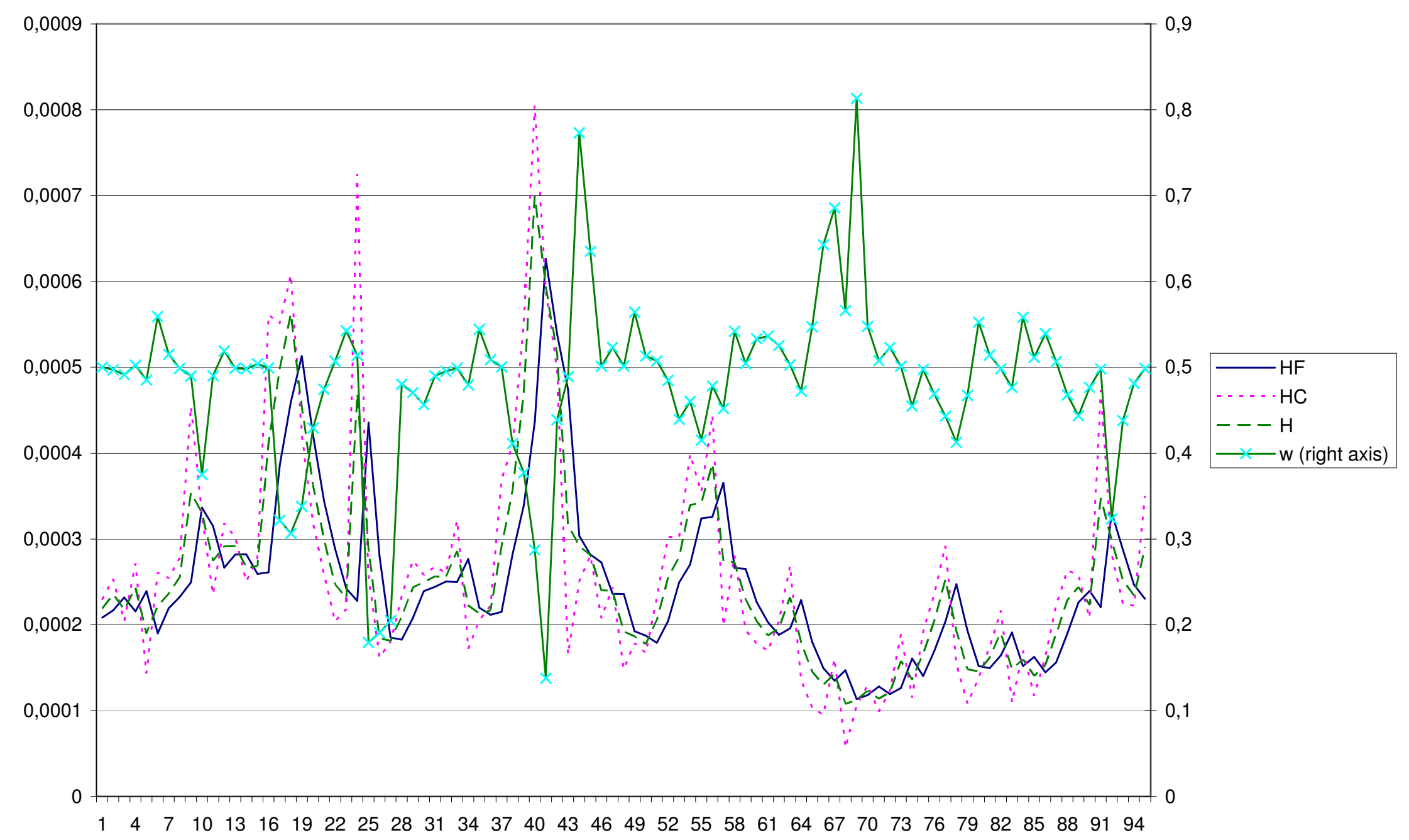


Figure 2: Parameter Estimates over time

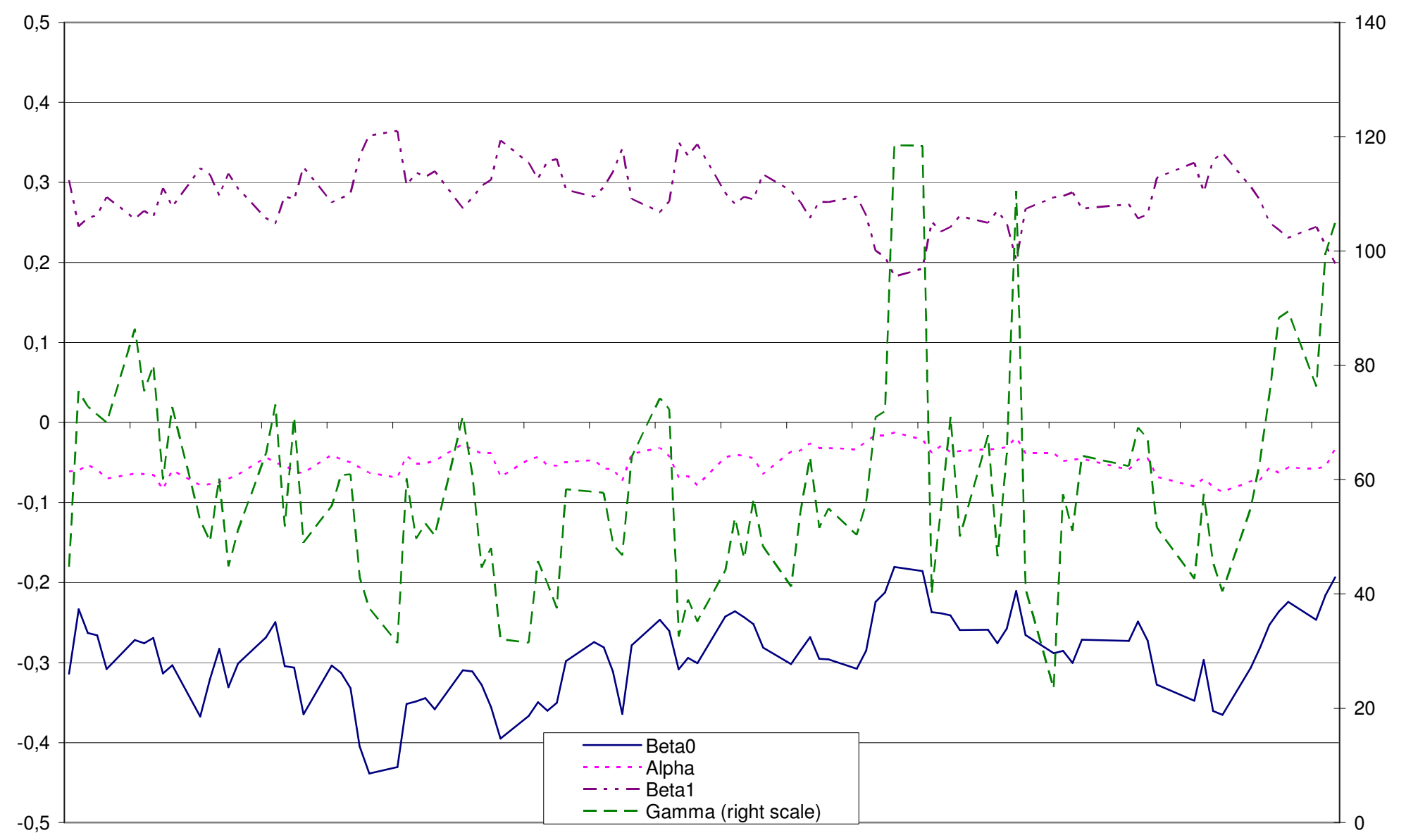


Figure 3: Estimated Volatility and in-sample Pricing Error over time

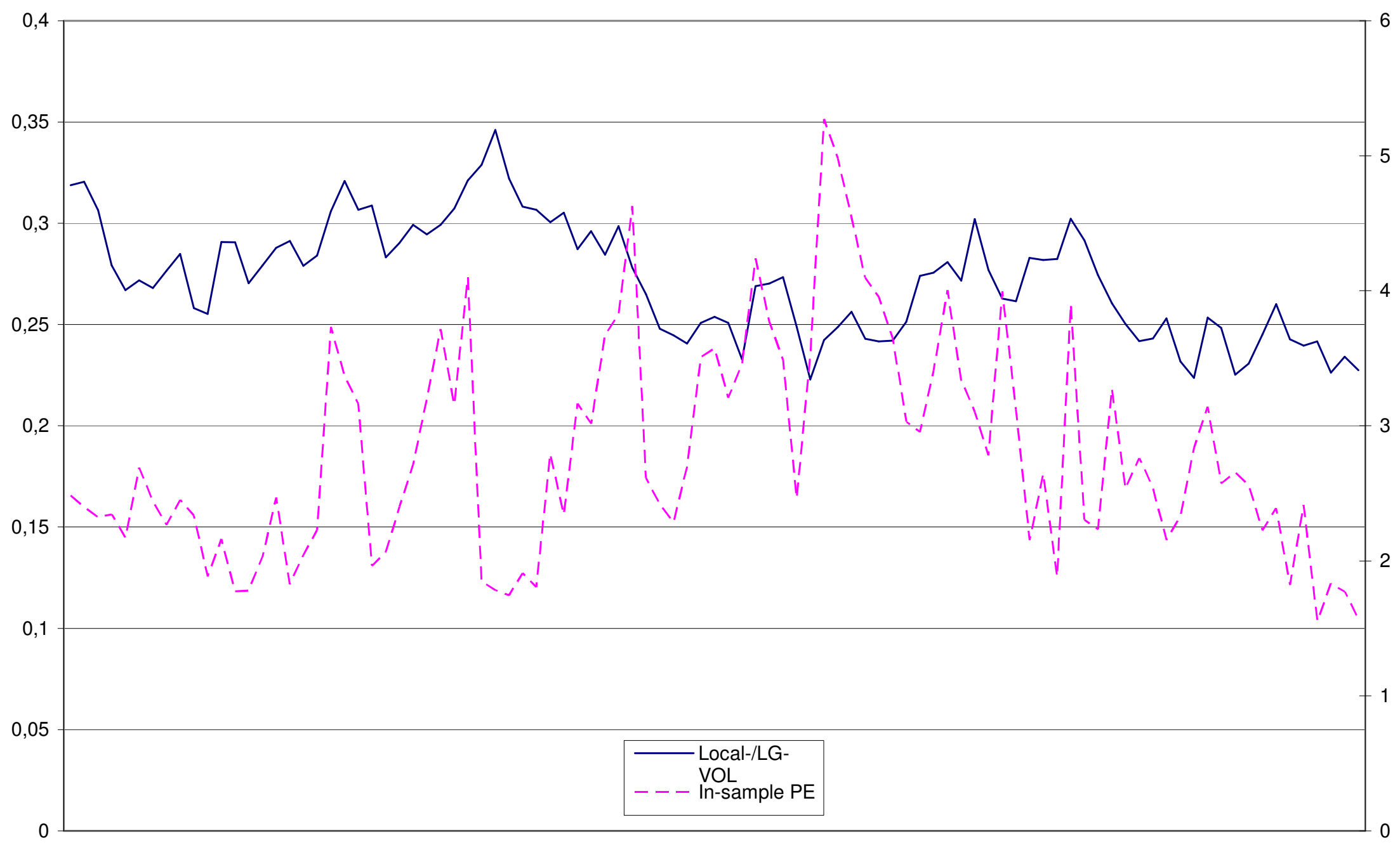

